\title{
Hot-cold Color Map
}

National Cancer Institute

\section{Source}

National Cancer Institute. Hot-cold Color Map. NCI Thesaurus. Code C85847.

A color map composed of warm and cool colors, varying from blue at the weakest intensity to red at the strongest and with a neutral color at the midpoint. It is useful for data where the sign is important. 